Progress Report for the Period October 1 through December 31, 1994

U.S. Army Engineer Waterways Experiment Station (WES) Support

to Department of Energy Rocky Flats Facility (DOE RF)

Saltcrete Processing

1. Summary: This report summarizes work authorized under Interagency Agreement DEAI34-93RF00467 to the WES for technical and scientific support to waste cementation and saltcrete processing operations. During this report period, tasks described in amendment M003 were initiated, some were completed, and an additional task (see 2b) not listed in M003 also was completed at the request of DOE RF. Summaries of task-specific activities are in four enclosures to this progress report. Other activities during this quarter included negotiation and initiation of amendment M004, to extend the period of performance and continue WES assistance to DOE RF.

\title{
2. Accomplishments:
}

a. Following acceptance of amendment M003 to the Interagency Agreement, the WES prepared Research Project Plan (RPP) No. 95-2, a copy of which is attached (enclosure 1). This Plan describes the ongoing work to be accomplished at the WES through January 1995.

b. On November 7, 1994, the WES received a copy of a document prepared by EG\&G Rocky Flats numbered TD94-DDT-001 and entitled "Analyses of Saltcrete." Review of this EG\&G document was undertaken by the WES team as described in RPP 95-2. Written review comments are attached (enclosure 2).

c. During FY 94, the WES had reviewed another EG\&G report, "Saltcrete Evaluation," dated August 16, 1993. During the current report period, the WES initiated and completed some statistical analyses of data tabulated in the earlier EG\&G report and prepared a written review to include these data analyses. A copy of the written review with results of the data analyses is attached (enclosure 3 ).

d. During the previous quarter, the WES had initiated scoping studies to confirm the formation of the crystalline phase darapskite from surrogate (nonradioactive) RF waste salt when mixed with portland cement. As part of a new task under M003, the WES continued these studies to assess the effectiveness of darapskite as a source of expansion and deterioration of saltcrete, and explored the mechanism by which deleterious reactions occur in surrogate saltcrete. These scoping studies and results of cycles of freezing and thawing and other variables are described in enclosure 4. Work on calculation of forces that could plausibly be generated by the crystallization of nitrate-sulfate salts in saltcrete will continue through January 1995. 


\section{DISCLAIMER}

Portions of this document may be illegible in electronic image products. Images are produced from the best available original document. 
3. Plans for Next Quarter: The work described in $2 . \mathrm{d}$ will be completed. Given that the period of performance for the existing Interagency Agreement has been extended through FY 95, the WES expects to undertake additional tasks delineated and agreed upon in discussions with $\mathrm{RF}$ representatives. The WES team recommends initiation of work on an alternative solidification technology applicable to RF waste salts for which WES has a patent pending.

\section{Enclosures}


CEWES-SC-A

2 Nov 94

RESEARCH PROJECT PLAN NO. 95-2

SUBJECT: Continuing Support to Waste Cementation and Saltcrete Operations at DOE Rocky Flats Facility

1. Principal Investigator: Lillian D. Wakeley, SC-A, ext. 3215

Project Coordinator: Toy S. Poole, SC-EM, ext. 3261

2. Sponsor and Authority: Department of Energy Rocky Flats Office (DOE/RFO), authorized under Interagency Agreement DE-AI34-93RF00467 and amendments through M003.

3. Objective: Provide technical review and scientific and engineering technical assistance to ongoing waste cementation operations at the Rocky Flats Plant. This assistance will include consultation about laboratory activities at RFO, review of documents provided by RFO, review of data related to operational parameters and wasteform performance, and expert assistance in data analysis, troubleshooting, and process modification.

4. Background: Research Project Plan 94-6, dated 14 Dec 93, gives applicable background information. The WES team participated in a site visit to RFO during 3Q FY 94, conducted scoping experiments on salt crystallization from materials similar to the saltcrete, and prepared written reviews of documents and summaries of laboratory sample-preparation techniques during FY 94. This RPP describes additional technical assistance to RFO building directly on accomplishments during FY 94.

5. Task Descriptions: The following task descriptions are modified from the Statement of Work attached to amendment M003 to the interagency agreement:" In addition to the specific tasks listed here, or in lieu of one or more of these tasks by agreement between RFO and WES, the WES team will continue to respond to requests for specific expert assistance on performance of batches of saltcrete produced at RFO during the period of performance of this project.

a. Task 1. Support for Saltcrete Petrographic Study. Most of this task was completed during 3-4Q FY 94. The WES team provided oral and written guidance to personnel at RFO who were engaged in petrographic analysis of saltcrete samples, to determine causes of wasteform expansion. RFO contract personnel. were not specifically trained in preparing and examining concrete-like specimens and identifying compounds common to portland-cement based materials and salts likely to occur in saltcrete. The 
CEWES-SC-A

2 Nov 94

SUBJECT:- Continuing Support to Waste. Cementation and Saltcrete Operations at

DOE Rocky Flats Facility

WES team observed sample-preparation and analysis procedures at RFO and recommended modifications and additions to these procedures to improve the output of petrographic analyses. Remaining under this task is WES review of the contractor's petrographic report from this study (to be provided during Nov by RFO).

b. Task 2. Written Review of EG\&G Saltcrete Evaluation Report dated 16 Aug 93. This report provides a thorough description of the saltcrete process and the nature of the saltcrete-deterioration problem. It also describes a number of laboratory experiments conducted in an effort to identify the cause of the expansion problem. Some specific conclusions were drawn from these experiments: The experimental data have not been analyzed statistically. The WES team will analyze these data to determine which of the results are strong enough to be used in supporting these conclusions. Also, the chemical and physical principles behind the experiments need to be reviewed to insure that the conclusions drawn from the results are plausible. A test, plan for additional work, if needed, will be developed as part of the written review.

c. Task 3. Plausibility of Salt-Crystallization Mechanism for Expansion of Saltcrete. Literature exists that describes the effect of salt crystallization on concrete and describes the theoretical forces that can be developed. This literature will be reviewed in the context of saltcrete. The WES team will calculate the expansion potential of the salts that form in the hydrated saltcrete wasteform. In addition, results of the scoping experiment conducted at WES following the RF visit in Apr 94 will be summarized as they relate to salt crystallization and wasteform cracking. This experiment investigated length change under various specimen storage conditions of a simulated saltcrete, and included petrographic analyses to identify salts formed before and after exposure to these conditions.

d. Task 4. Wasteform Performance Envelopes (if funds available). Published literature from other applications of portland-cement systems used for solidification of salt wastes will be reviewed to determine the ranges of waste loading that have been used successfully. The purpose of this review is to determine if the salt loadings used at RF are unrealistically high, or if performance excursions are more likely to be related to materials and conditions.

6. People and Responsibilities: The WES team includes Drs. Lillian Wakeley, Toy Poole, and Phil Malone and Mr. Pete Burkes. Mr. Burkes provided the written summary of specimen-preparation techniques under Task 1. Wakeley, Burkes, and Malone will review the EG\&G petrography document provided under Task 1 . Poole will analyze the data in Task 2 and draft the review report. Poole will conduct the literature search 
SUBJECT: Continuing Support to Waste Cementation and Saltcrete Operations at DOE Rocky Flats Facility

necessary as background to Task 3 and coordinate calculations with Malone. All team members contributed to the scoping study to be summarized under Task 3. Malone will conduct the literature search necessary for Task 4, if it is initiated. Tasks 1 through 3 are underway and should be completed during Jan 95. Progress on these three tasks will be reported in the report for 1Q FY 95, with written input to be provided to Dr. Wakeley by 20 Jan 95 . Initiation of Task 4 will be delayed to accommodate other task requests by RFO. The completion date for Task 4 and the total project is unknown at present, because RFO is initiating another amendment to extend the period of performance.

7. Schedule and Funding: Scheduling is summarized in para 6 . A total of $\$ 18 \mathrm{~K}$ is .. available to Petrography and Chemistry Group for their participation between 1 Oct 94 and $20 \mathrm{Jan} 95$. Also, another $\$ 18 \mathrm{~K}$ is available to Poole for the same time period.

8. Records and Reports: Dr. Wakeley will maintain a complete set of project records, and all team members will provide copies of all laboratory notes, petrographic reports, and other data to her for this purpose. Quarterly technical reports will be forwarded to DOE/RFO by the end of the month following the end of each quarter. Written reviews will be enclosed in these reports. Team members will provide written summaries and updates of project files to Dr. Wakeley by the 20th of each month, and Dr. Wakeley will prepare the quarterly reports from this input.

NOTE: Project records are currently out of date, and will be updated to include all accomplishments on Tasks 1,2, and 3 during FY 94. All team members will provide this input to Dr. Wakeley by 18 Nov 94.

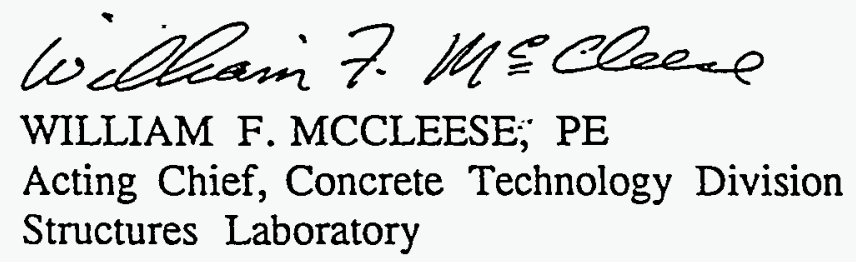

CF:

Mather Wakeley.

Ballard Malone

McCleese Poole (2)

Ragan Burkes

Brabston 
CEWES-SC

25 January 1995

Review of TD94-DDT-001, Analyses of Saltcrete

1. Background: Concrete Technology Division, Structures Laboratory, has been tasked under Interagency Agreement DE-AI34-93RF00467 to review the document prepared by EG\&G Rocky Flats, entitled "Analyses of Saltcrete" and dated August 16, 1994. The WES received a copy of this document on November 7, 1994.

2. Purpose of EG\&G Investigation: Some of the plywood crates containing cast-in-place blocks of saltcrete (waste salt, brine, and Type I portland cement) have deformed and split along nailed edges some time after hardening of the saltcrete. Saltcrete crates cannot be shipped in this condition. Failure of the plywood crates was attributed to expansion of the saltcrete. The purpose of the investigation reported in TD94-DDT-001 was to identify the mechanism of the apparent expansion.

\section{A. MAJOR COMMENTS}

\section{Darapskite Formation and Expansion of Saltcrete.}

a. The main conclusion of the report is that the hydrated double salt, darapskite $\left(\mathrm{Na}_{3}\left(\mathrm{NO}_{3}\right)\left(\mathrm{SO}_{4}\right) . \mathrm{H}_{2} \mathrm{O}\right)$, is the principal cause of expansion in the saltcrete. Note that darapskite is a sodium nitrate-sulfate salt, not a nitrate-sulfite $\left(\mathrm{SO}_{3}\right)$ as indicated in the report.

b. It is important to understand the phase relationships in a solution containing sodium sulfate and sodium nitrate. According to published references, darapskite has "incongruent solubility, that is it crystallizes from a solution in which the relative amounts of its component ions differ from those of the mineral" (Erickson and Mrose, 1970). If excess sodium nitrate is present, then at equilibrium all of the sulfate should be present as the double-salt darapskite (except in solutions with high chloride ratios). Most natural salt deposits that have arrived at equilibrium. contain darapskite and sodium nitrate with no sodium sulfate present. If this rule applies, the presence of sodium sulfate patterns in the X-ray data presented in the EG\&G report suggests that the saltcrete is not at equilibrium and still has the potential to form more darapskite and continue to expand. Because the X-ray data are not quantitative, the full potential for expansion cannot be predicted because we cannot determine the quantity of potential reactants.

\section{References to Gas Generation:}

a. There is no reason with the data available in this report for suggesting that the expansion of the saltcrete is due to gas generation. None of the constituents recorded as being present in the waste would normally react with the portland cement to produce gas. No conclusive evidence of gas generated in place was found in the investigation. Small voids (referred to in the report as microvoids) that did not contain crystals are most probably cavities left by bubbles of entrapped air. 
b. The reference to gas generation (page 12, paragraph 1) should be considered carefully. In discussions of gas in concrete, researchers not fully acquainted with the saltcrete process may assume that hydrogen was generated in the solidification system. If any process generated hydrogen in the closed half-crates, the entire system would be judged as dangerous because of the flammable and explosive nature of air-hydrogen mixtures. Gas generation as an expansion mechanism should only be discussed if there is reason to believe it has occurred or if analysis of the headspaces in the half-crates has indicated that the gas in the headspaces is different in composition from the surrounding air. These events are not indicated in the report.

5. The Role of Calcium Chloroaluminate Hydrate. The role of the calcium aluminate chloride (calcium chloroaluminate hydrate) phases in expansion is not clear from the report. Calcium chloroaluminate hydrate formation is known to cause expansion in concrete containing portland cement and sodium chloride. Calcium chloroaluminate hydrate is present as two different hydrates, but it is difficult to argue that the transition from one hydrated phase to another hydrated phase causes major expansion unless it can be shown that the two phases involved have significantly different specific volumes (see page 21, paragraph 1, of the subject report). It is more probable that the expansion discussed in this report (and noted by other researchers) is related to the reaction of chlorides from waste salts with the calcium aluminate and calcium aluminate hydrate in the cement paste, long after the saltcrete has set. It should also be noted that the report does not produce any petrographic data to show expansion cracks associated with the calcium chloroaluminate hydrates; in fact, Figure 16 shows contraction cracking associated with a void filled with calcium chloroaluminate hydrate. Calcium chloroaluminate hydrate formation is probably one of the causes of expansion in the solidified wastes, but without more work it is impossible to estimate to what extent this reaction is responsible for the overall expansion of saltcrete.

6. XRD Data: The statement in the conclusions that there may be other phases that exist that cause expansion is not well-supported. The XRD data are fairly comprehensive, and almost all of the major peaks in the powder pattern are identified. None of the petrographic work suggested the presence of expansive amorphous phases (undetectable by XRD).

7. Finite Expansion: The statement in the conclusions that the expansion is finite and will decrease with time is not supported by the EG\&G study. Experience with natural darapskite deposits suggests that if sodium sulfate, darapskite, and sodium nitrate are present, more darapskite will form. Small crystals of darapskite and/or calcium chloroaluminate may be dissolving and providing more materials in solution to nucleate on the larger crystals. The large crystals may be growing while the small crystals dissolve. The voids left by the small crystals do not have to be filled, and the net result is an increase in volume and pressure on the surrounding saltcrete and the crate. The experimental work that was done on calcium chloroaluminate hydrates suggests that temperature cycling is important in expansion. If temperature changes are driving the recystallization, the number of freeze-thaw cycles may be more important in estimating the amount of expansion than the time elapsed since placing the saltcrete in determining if the reactions producing expansion have come to equilibrium. If old 
crates are subjected to a number of temperature cycles and expansive phases continue to rearrange-themselves into larger masses, there may be additional crate failures. Without knowing all of the mechanics of the saltcrete expansion, it is difficult to predict that the waste, if repackaged, will not break a second crate.

8. Need for Additional Study: A section on additional investigations should be added to the EG\&G report or issued as a separate document. The report suggests additional investigations are needed to optimize saltcrete, but more specific recommendations are needed. For example, if gas bubbles are suspected to have formed in the saltcrete, some attempt to extract and analyze the gases associated with saltcrete should be made as soon as possible. If calcium chloroaluminates are suspected to have contributed to the expansion, additional model studies are needed to understand this problem. The proposed expansion reaction based on the formation of darapskite has not been reproduced in the laboratory with a non-radioactive simulated saltcrete mixture. Temperature cycling and recrystallization should be evaluated in the laboratory. Studies to determine if or what modifications to the saltcrete mixture would diminish formation of deleterious phases should be recommended. Physical changes in packaging, to accommodate saltcrete expansion without damaging the crates, also should be considered. All of these efforts are needed to improve waste treatment and consistently produce a wasteform that needs no further treatment prior to disposal.

\section{B. ADDITIONAL COMMENTS}

9. Additional comments follow:

a. Page 2, paragraph 1: "Slightly contaminated" means "slightly contaminated with radioactive materials."

b. Page 2, paragraph 1: RCRA is Resources Conservation and Recovery Act?

c. Page 2, paragraph 2: How many is "a few instances"?

d. Page 2, paragraph 2: "Breaks the seals" means exerts enough force to deform the plywood and pull out nails.

e. Page 2, paragraph 4: Should include the chronological age of the lab samples.

f. Page 2, paragraph 4: How many freeze-thaw cycles?

g. Page 3, paragraph 3: Samples were front packed without sieving so there may be some orientation problems and a range of grain-sizes may be present. Both of these problems can make identification and quantification of the mineral phases difficult. 
h. Page 4, paragraph 3: SEM with EDX can often identify even materials without good crystalline-morphology.

i. Page 5, paragraph 2: What is the size of microvoids and micropores? How are they differentiated?

j. Page 8, Figure 3: What is the sample number?

k. Page 9, Figure 4: What is the sample number?

1. Pages 10 and 11: Table is confusing. An alternative is to add a separate table identifying all the samples as to crate identification number, condition of crate, etc. It would be useful to add a table summarizing all the crystalline phases present and indicating which samples appeared to have each phase as major, minor, or trace components (qualitative indicator of amounts).

m. Pages 13-18: None of the captions on the figures identify the core samples from which the photomicrographs were made nor the history of the material pictured (variables such as specimen age, number of freezing cycles, proximity to visible fractures, etc.). More information about the examples pictured would be useful.

n. Page 19: Table 2 presents chemical analyses of various saltcrete samples, but the report does not relate the expansion problems to variations in chemical composition.

Formation of darapskite is not limited to a condition where sodium sulfate, sodium nitrate, and water are present in equal molar concentrations. It forms when some of each is present and other conditions are met.

o. Page 20: The presence of calcium carbonate does not indicate cement hydration. It is not a hydration product of portland cements.

p. Page 20: Table 1 does not present quantitative data on amounts of darapskite present. The data do not support the conclusion that bulged areas have more darapskite than nonbulged areas. It may be true, but it is not supported by the data presented. Also, leaving a void where material is removed from a solid is not a plausible cause of expansion.

q. Page 21, paragraph 1: More work should be done on the calcium chloroaluminate hydrates. Various members of this phase group are stable both above and below $28^{\circ} \mathrm{C}$. The current data are not adequate to prove that the phase transformation associated with temperature cycling is responsible for the expansion. XRD of a sample after the first freezing cycle would have shown whether or not a phase transition was occurring. 
r. Page 21, paragraph 2: "Silicone" is a misspelling; this should probably be "silicon." The silicon probably was found using the SEM with analytical attachment. Since cement is primarily calcium silicate, the presence of high localized concentrations of silicon is expected.

s. Page 21, paragraph 2: The amount of calcium chloroaluminate hydrate that has formed cannot be adequately determined without running standard mixtures. The statement concerning the large amount of calcium chloroaluminate hydrate in contrast to the small amount of aluminum present is not backed up by quantitative data at this point.

t. Page 21, paragraph 2: The comment that other phases exist that are not detected should be reconsidered. The investigation was fairly complete, and even gel phases should have been detected by optical microscopy even though they could not be identified by XRD. If additional expansive phases are present, they should be relatively minor components.

u. Page 21, paragraph 3: The report mentions the problem of darapskite formation, but the problem of recystallization may be equally important. If in the temperature cycling the fine crystals of darapskite are dissolving and reprecipitating, perhaps nucleating, on the larger crystals to cause selective growth of large crystals, the expansion problem may not end when all of the sodium nitrate and/or sodium sulfate is used up. Expansion may be a function both of amount of expansive phase and of its mobility and extent of recrystallization.

v. Page 22: The problems that make some crates of saltcrete unshippable are not "fatigue," which would be loss of strength of the solid. In fact, if the saltcrete lost strength, it might not crack so easily, but might deform plastically and accommodate new-formed crystals, rather than exerting outward pressure to split the crates. There is no evidence that phase changes within calcium chloroaluminate hydrates could cause the observed crate damage. The formulae presented for these phases are unusual; a reference to published work is needed. 
CEWES-SC

Poole - January 31, 1995

c:Itext.docirf006.wp

\section{REVIEW OF CONNELL ET AL. "SALTCRETE EVALUATION" REPORT \\ DATED AUGUST 16, 1993}

\section{COMMENTS PREPARED BY U. S. ARMY ENGINEER WATERWAYS EXPERIMENT STATION}

\section{A. GENERAL COMMENTS}

The report is a thorough summary of unacceptable performance of saltcrete. The descriptions of problems are well developed and investigations well.conceived. There are several areas in which experience at the WES might be helpful. These involve parts of the process that are affected by physical and chemical processes involving cementitious materials. These are swelling of hardened saltcrete, mixture proportioning, and time of setting and viscosity of fresh saltcrete. Following are general comments in these areas. Detailed notes keyed to parts of the text are included in Part B.

\section{Swelling of Hardened Saltcrete}

The history of the swelling problem clearly supports the hypothesis that it is related to the amount of salt and the chemical composition of the salt. The frequency of swelling increased when amount of nitrate decreased relative to the amounts of sulfate and chloride, a change that occurred when plutonium production ceased. The problem was solved by reducing the salt loading of saltcrete from $50 \%$ to $30 \%$. The frequency increased again when salt loading was increased to $35 \%$. That swelling does not always occur indicates that other variables are involved. The purpose of the accelerated aging tests was apparently to try to identify some of these variables.

The freezing-and-thawing test and the wetting-and-drying test, adapted from ASTM D 560 and D 559, respectively, were reasonable approaches to looking at the effects of variation in environmental conditions experienced by the halfcrates during storage at Rock Flats. In the case of the freezing-andthawing test, freezing probably did not actually occur. The freezing point was depressed by the saltsaturated aqueous phase of the saltcrete. However, this test achieved extreme temperature cycling. Some modifications to the tests are recommended.

The freezing-and-thawing test would be improved by sealing specimens in a container so that they will not dry out during the thawing cycle. The relatively high temperature $\left(55^{\circ} \mathrm{C}\right)$ and relatively high surface-volume ratio of the specimens make them highly susceptible to desiccation. Once a critical level of desiccation occurs, further testing may not be meaningful.

The wetting-and-drying test may be improved by exposing the specimens to a mist or a fog during the wetting cycle. Once the specimens desiccate at the $55^{\circ} \mathrm{C}$ exposure, subsequent exposure to $100 \%$ relative humidity for a few hours is probably insufficient to completely re-hydrate them to a condition close to the original saltcrete.

The cementitious materials chosen for the accelerated-aging studies reasonably cover the range of chemical compositions $\left(\mathrm{C}_{3} \mathrm{~A}\right.$ was the compound of interest) of portland cements. The inclusion of a 
Class $\mathrm{F}$ and a Class $\mathrm{C}$ fly ash represents the two major variants of coal fly ash, but the chemistry of Class $\mathrm{C}$ fly. ashes varies considerably among sources, so that no single material can accurately represent the behavior of the class of material. The Types $\mathrm{V}$ and I/II portland cements used did not differ significantly in $\mathrm{C}_{3} \mathrm{~A}$ content ( $5 \%$ and $6 \%$, respectively), so for practical purposes, they represent replications of the same relatively low $\mathrm{C}_{3} \mathrm{~A}$ content. The Type I cement had a $\mathrm{C}_{3} \mathrm{~A}$ content of $12 \%$, which is close to the maximum amount found in portland cements.

The wetting-and-drying tests did not reveal any significant variation in performance among the combinations of cementitious materials examined. The predominant effect was a relatively uniform mass loss, which would be expected given the $32 \%$ water content and open microstructure of saltcrete and the predominantly drying conditions of the test. There was also a small but consistent volume reduction, which was probably a drying-shrinkage phenomenon related to the conditions of the test.

The freezing-and-thawing testing did reveal some significant materials-related effects, particularly in the tests involving the "actual salts." Large volume increases were evident with both the actual and surrogate salts, but the differences among cementitious materials was statistically significant only in the former. It is not clear why salt type mattered. The chemistries of the actual and surrogate salts were not given. If they are the same as the salt chemistries used in the viscosity testing, then molar ratios of the sulfate, nitrate, and chloride anions, which are the anions of principal interest, were close to the same. Differences in relative concentrations of these anions could result in different performance properties. The preparation of the surrogate salts involved evaporation of water, so the exact water-cement ratio of the final mixture was not obvious. Differences in water content could be critical. The temperature was cycled over a wider range in the actual-salt testing (20 to $\left.55^{\circ}\right)$ than in the surrogate-salt testing $\left(-12\right.$ to $\left.55^{\circ} \mathrm{C}\right)$. Actual-salt specimens showed a greater range of expansive behavior than the surrogate-salt specimens. Volume changes ranged from $-2 \%$ to $17 \%$ among the various materials examined. Volume change in surrogate-salt specimens ranged from about $2.5 \%$ to $9 \%$.

Two statistically significant results concerning types of materials were revealed from the actual-salt testing. First, high- $\mathrm{C}_{3} \mathrm{~A}$ cements and mixtures of these cements with fly ash expanded more than low- $\mathrm{C}_{3} \mathrm{~A}$ cements and mixtures. Second, Class $\mathrm{F}$ fly ash reduced the amount of expansion, relative to the pure-portland-cement condition, while Class $\mathrm{C}$ fly ash had no effect that was statistically detectable.

The $\mathrm{C}_{3} \mathrm{~A}$ effect suggests an important role of one or a combination of three compounds formed when $\mathrm{C}_{3} \mathrm{~A}$ hydrates in the presence of nitrate, sulfate, and chloride ions. These compounds are calcium nitroaluminate, calcium sulfoaluminate, and calcium chloroaluminate, respectively. The nitrate compound is uncommon in publications from the concrete literature because of the infrequency of nitrates in concrete, except in low concentrations as an antifreezing admixture. Sulfate and chloride compounds are commonly identified in concrete. Calcium sulfoaluminate is a compound that can cause serious concrete deterioration due to expansion when it forms in large quantities after a rigid matrix is formed in concrete. Calcium chloroaluminate is also expansive, but much less so, and is not generally considered to be a major cause of concrete deterioration. Class F fly ash commonly reduces the volume change associated with these reactions in conventional concrete. Class $\mathrm{C}$ fly ash often does not. The expansive nature of these compounds does not require temperature-cycling to be expressed. The effect of temperature cycling may be to affect the size and distribution of crystals. 
The $\mathrm{C}_{3} \mathrm{~A}$ effect immediately suggests an extreme case of sulfate attack as the cause of the expansion-problem in saltcrete. Two things argue against this. First, in WES experience, the lessexpansive chloride compound forms preferentially when both chloride and sulfate are present in large quantities. Second, regardless of which phase forms, any expansive compounds that form will probably form early in the hydration history, because of the highly reactive nature of $\mathrm{C}_{3} \mathrm{~A}$. Given the long setting times of saltcrete, all of the $\mathrm{C}_{3} \mathrm{~A}$ probably hydrates and forms these expansive phases when the material is still plastic, and hence no further expansion would be expected once the material is hardened.

The large volume changes associated with the freezing-and-thawing testing suggests that some kind of crystallization process is operative in saltcrete expansion. The effect of temperature cycling may be to cause a relatively few large crystals to grow at the expense of relatively more small ones. As the small crystals dissolve and the compounds from them recrystallize as large crystals, the effect is a net movement of mass (and hence volume) from one location in the microstructure of the saltcrete to another (possibly to a preexisting crack surface). Since the microstructure is rigid, this results in creation of porosity at one place and expansion at another. Conceivably, $\mathrm{C}_{3} \mathrm{~A}$-based compounds play a role in such a process.

In conclusion, temperature cycling may be a very important variable in the saltcrete expansion process. It is important to determine what chemical phases form to cause the expansive reaction in saltcrete. There is insufficient information in the report to do this. It can be done with a combination of XRD and SEM. Temperature cycling of laboratory specimens should be a very useful way to investigate this problem.

\section{Mixture Proportioning}

Mixtures are proportioned first by determining the specific gravity of the brine. This measurement determines the amount of dry salt to be added. A fixed mass of portland cement is used. The amount of water in the saltcrete depends on the ratio of brine to dry salt used. Therefore, variations in specific gravity of the brine or errors in determining the specific gravity of the brine will cause errors in the water content of the saltcrete. The amount of water can affect viscosity, time of setting, propensity for cracking, ultimate strength, and potentially the swelling reaction. The target in the process is to achieve a given level of salt loading of the saltcrete. Water content is expected to vary some.

There was concern reported that the equipment used to measure the specific gravity of the brine was inadequate, thus causing batching errors. Reading errors in determining the specific gravity of brine probably do not cause a serious batch-proportion error. A reading error of 0.02 specificgravity units would result in a water-cement ratio error of 0.026 , which is probably not critical. Specific-gravity reading errors of 0.05 would result in a water-cement ratio error of 0.065 , which might be significant. But, errors this large were not indicated.

Actual variation in specific gravity of brine among production runs could cause a watercontent problem. Specific gravities of brine apparently do vary from 1.21 to 1.30 . Over this range, salt loadings decrease from $27 \%$ to $25 \%$ and water-cement ratios increase from 0.79 to 0.83 . These changes may have detectable effects on the viscosity of the mixture and on volume changes. A laboratory analysis of the effect of changing mixture proportions on viscosity would be beneficial. 


\section{Time of Setting}

The peak of the data curve for temperature versus time was used as a measure of setting time for comparisons within and among batches of saltcrete. This is an unconventional way to measure time of setting, in that it does not measure the physical property directly. However, the timing of the exotherm is probably strongly correlated with time of setting; and so it is a reasonable measure for comparative purposes. In conventional concrete, setting occurs before the peak in the exotherm is reached. If this is true of saltcrete, then the time of setting measured by temperature may be a little longer than would be observed by direct-measurement of the property.

Data were presented for four production runs. Mean time of setting ranged from 6.7 days to 10.2 days. Variation among production runs was significantly greater than variation among halfcrates within production runs. As indicated in the report, variation in the chemistry of the salt among production runs could account for the variation in time of setting. Another source of variation could be changes in the water-cement ratio that occur as a result of the variations in the specific gravity of the brine. As discussed above, mixture proportions are somewhat dependent on the specific gravity of the brine. Time of setting in conventional concrete is highly sensitive to water-cement ratio. Specific gravities of the brine used in these production runs were not included in the report, so this idea cannot be directly evaluated. Production data probably exist that would allow an analysis of the relationship between the specific gravity of the brine and the time of setting of corresponding saltcrete.

If the data in the report can be taken as a random sample of all production runs, then one would expect an average time of setting of 8.0 days, but individual runs might vary by \pm 2.9 days from this mean $(2 \mathrm{~s})$.

The accelerated aging tests indicated that use of Class $\mathrm{F}$ fly ash might help solve the swelling problem. A negative effect of this practice would be to increase time of setting. Class $F$ fly ashes do not participate in the time-of-setting reaction, and since some of the portland cement has been replaced, the mean distance among cement particles is larger than in a mixture made without fly ash, and so time of setting is longer.

Viscosity

The study concluded that choice of cementitious materials did not affect viscosity, with the exception of attapulgite clay, which had a strong negative effect. This is a statistically sound conclusion from the data. Also, the results of the study that attempted to use surrogate salts to investigate the viscosity problem indicated that crystal size of the surrogate salt interfered with the simulation of the actual-salt problem. Perhaps these two results indicate that particle-size distribution (PSD) of solids, rather than chemistry, is the predominant property determining viscosity. Modification of the evaporation process or selection of cementitious materials that have different PSD characteristics could help solve the viscosity problem.

\section{B. NOTES ON SPECIFIC SECTIONS OF THE REPORT}

Sections 1 and 2 (through 2.3) are largely descriptive. 
This report has a very wide scope, covering many aspects of the saltcrete operation and wasteform problems:-Some of these aspects are outside the technical experience of the WES team and will not be commented on. Other areas of the report coincide with our expertise. Comments on these sections follow.

\subsection{Evaluation of Saltcrete Inventory}

\subsubsection{Wasteform Swelling.}

This section includes a good time-line history of the swelling problem. It is clear from comparison with history developed in Section 1 that swelling is related to change in salt chemistry that occurred when plutonium production ceased and nitrate-sulfate ratios decreased. Later problems appear to be associated with increase to $35 \%$ waste loading that was instituted to reduce volume of processed waste.

Only a fraction of the total number of crates expanded to failure. It is not clear from the description whether the swelling crates came from few batches that were perhaps unusual in some way or whether they are random with respect to batches of saltcrete made. If they tended to cluster in certain batches, then this would suggest that some batch-specific properties were operative, such as variation in salt chemistry or salt physical properties. If swelling crates were not associated with certain batches of saltcrete, then that would suggest that the phenomenon was caused by some peculiarity of handling or storage.

\subsection{Certification Issues}

\subsubsection{Process Controls}

\subsubsection{Determination of Solids Concentration in Brine}

Solids concentration in brine is determined from the specific gravity of the brine. A number of sound recommendations were made in the report about how to improve this measurement. Since the mixture proportions of saltcrete are primarily determined by the specific gravity of the brine, it might be useful to know how much an error in specific gravity measurement affects the proportions of salt, cement, and water in saltcrete. Using the "Saltcrete Specific Gravity Calculation Chart" from OAP-374-16 as a guide to saltcrete proportions, the effect on saltcrete proportions can be calculated. For this comparison, mixture proportions for a brine with a specific gravity of 1.21 were calculated. Then, assuming an incorrect measure of specific gravity of 1.20 on a brine that was actually 1.21 , another set of mixture proportions would result. These are compared in Table 1 : 


\begin{tabular}{|c|c|c|}
\hline $\begin{array}{l}\text { Table 1. Comparisc } \\
\text { Specific Gravity } 1.2\end{array}$ & $\begin{array}{l}\text { f Proportions of a } \\
\text { correctly Measur }\end{array}$ & $\begin{array}{l}\text { Saltcrete of } \\
\text { at } 1.20 \text {. }\end{array}$ \\
\hline \multirow{2}{*}{ Component } & \multicolumn{2}{|c|}{ Weight (lbs) } \\
\hline & Sp. Gr. $=1.20$ & Sp. Gr. $=1.21$ \\
\hline $\begin{array}{l}\text { Brine } \\
\qquad \begin{array}{l}\text { salt }^{1} \\
\text { water }\end{array}\end{array}$ & $\begin{array}{r}472 \\
84.9 \\
382.6\end{array}$ & $\begin{array}{c}480 \\
90.9 \\
389.1\end{array}$ \\
\hline Dry Salt & 238 & 230 \\
\hline $\begin{array}{l}\text { Total Salt } \\
(\%)\end{array}$ & $\begin{array}{l}322.9 \\
(27.2)\end{array}$ & $\begin{array}{l}320.9 \\
(26.7)\end{array}$ \\
\hline Cement & 490 & 490 \\
\hline Total Weight & 1200 & 1200 \\
\hline water-cement ratio & 0.781 & 0.794 \\
\hline cement-salt ratio & 1.517 & 1.527 \\
\hline
\end{tabular}

The difference in critical properties, such as total salt, water-cement ratio, and cement-salt ratio, does not vary significantly for this size reading error. A reading error of 0.05 would result in an error in $\mathrm{w} / \mathrm{c}$ of 0.065 , which probably would result in a noticeable change in workability properties. The WES team is not aware of a relationship between viscosity and w/c for saltcrete with which to verify this judgement.

Specific gravities apparently vary from 1.21 to 1.30 (Table 2.5.1.2-1). Over this range, salt loading decreases from $27 \%$ to $25 \%$ and w/c increases from 0.79 to 0.83 . These changes may have a detectable effect on the viscosity of the mixture. A laboratory analysis of the effect of changing mixture proportions on viscosity would be beneficial.

\subsection{Time of Setting}

The time of maximum temperature rise is used as an indicator for time of setting. This is probably a meaningful indicator for this system, although actual setting, as perceived for conventional concrete, probably occurs sometime before that. Time of setting instruments and procedures exist that could be used for this if it is necessary to justify this part of the procedure by standard methods. One such method, ASTM C 403 or C 1117 (both use the same apparatus) could probably be used on the saltcrete while in the halfcrate, requiring no separate specimens be made.

An analysis-of-variance calculation (see table below) of the time of setting data in Table 2.6-1 indicates that setting time varies more among batches than among halfcrates within batches. This could be a result of changes in brine chemistry among batches, as was hypothesized for some of the 
viscosity data, but it could also be partly due to variations in water-cement ratio that occur because of changes in-specific gravity of the brine. Conventional concrete is very sensitive to changes in this property.

\begin{tabular}{||l|l|l|l|l|l||}
\hline Analysis of Variance Among Production Runs, Time of Setting, Data from Table 2.6-1 \\
\hline Source of Variation & $\mathrm{DF}^{(1)}$ & Sum of Squares & $\begin{array}{l}\text { Mean } \\
\text { Square }\end{array}$ & $\mathrm{F}^{(2)}$ & $\mathrm{P}^{(3)}$ \\
\hline Among Production Runs & 3 & 29.22 & 9.738 & 15.4 & 0.0001 \\
\hline Within Production Runs & 13 & 8.24 & 0.633 & & \\
\hline Total & 16 & & & & \\
\hline
\end{tabular}

(1) DF - degrees of freedom

(2) $\mathrm{F}$ - standard output of analysis of variance

(3) $\mathrm{P}$ - probability of achieving larger $\mathrm{F}$ by chance

\subsection{FORMULATION OPTIMIZATION}

\subsubsection{Approach.}

The formulation study evaluated different cementitious materials for their effect on viscosity and on durability. This is very reasonable since cementitious materials vary considerably in chemical and physical properties, particularly when fly ashes are included, and these almost certainly affect the rate of hydration (and hence viscosity) and durability. No chemical and physical properties of the materials were included in the report (except $\mathrm{C}_{3} \mathrm{~A}$ contents of the portland cements were reported in the Conclusions). Citing the type of cement (I, II, III, V) or the class of fly ash (F, C) approximately defines some properties, but others are totally undefined by this classification.

Much of the choice of materials was apparently based on the suspicion that sulfate attack might be an important problem. This is reasonable given the amount of sulfate ion in the salt mixture. However, it is likely that the high chloride content will react preferentially with the aluminates in the cementitious materials to form calcium chloroaluminate, and calcium sulfoaluminate (ettringite), the . principal reaction product that occurs in sulfate attack, will not form (Poole, 1993). Calcium chloroaluminate is considered to be mildly expansive, but not nearly as expansive as ettringite.

There are a few technical inaccuracies in the paragraph that starts on the bottom of page 3-2 and continues onto page 3-3. Ettringite does form early in the hydration history of cements, but in the case of portland cement, where sulfate contents are low, it acts as a retarder. Where sulfate and aluminate contents are high, such as with expansive cements and perhaps saltcrete, formation of large quantities of ettringite would potentially play an important role in setting behavior. Ettringite is not unstable in calcium silicate hydrate as long as sulfate concentrations are high. It does decompose to calcium aluminate monosulfate when sulfate concentrations become low.

The next paragraph on page 3-3 accurately describes effects sometimes shown by fly ashes in conventional concrete. These may not apply to saltcrete. Much of the durability enhancement 
contributed by fly ash to concrete is dependent on the concrete being cured to some reasonably advanced.level before being exposed to the aggressive agent, in this case sulfate. The fly ash can reduce the permeability and hence the delivery rate of the sulfate ion to reaction sites around aluminate particles. In the case of saltcrete, the aggressive agent is in high concentration before any curing takes place. For this reason, permeability of the saltcrete is probably not a very important property; the sulfate ion does not need to diffuse into the mass.

\subsection{Viscosity Measurements of Formulations.}

Note that viscometer data referenced on page 3-7 as in Table 3.2.1.2-2 are actually in Appendix C, Table 2.

The part of the viscometry work that involved surrogate salts (page 3-19) identified that crystal size was an important factor in determining viscosity of saltcrete. In addition to the idea that variations in the chemistry of the waste salt might affect viscosity, perhaps crystal size of waste salt should also be investigated if it is plausible that variation in this property is occurring among different batches of waste salt.

Another potential avenue of research is to look at the effect of particle-size distribution of cementitious materials on viscosity. This is mentioned in paragraph 4 of the Conclusions (page 325). That there were no large variations in viscosity attributable to differences in cement chemistry is not too surprising, even though cement chemistry would be expected to be important in conventional concrete, since the high salt concentrations retard the cement hydration markedly. Conceivably, the viscosity problem is mostly a particle-size distribution problem, both of the salt and of the cementitious materials. Particle-size properties of cements and fly ashes vary considerably. For example, oilwell cements are commonly ground to very coarse particle sizes to achieve extended workability. Some portland cements are ground to much more uniform particle sizes than others, significantly affecting rheological properties.

Paragraph 5 of the Conclusions (page 3-25) comments that fly ash is considered for use because it reduces the mobility of hazardous constituents, binds water, and reduces cost. Except for the reduction in cost, these may be misconceptions of the effects of fly ash. Fly ash does not bind water any more effectively than equal amounts of portland cement. In saltcrete, the $\mathrm{pH}$ may be low enough that the pozzolanic reaction between calcium hydroxide (from hydrating portland cement) and the fly ash is retarded. The restriction on mobility of hazardous materials is strongly dependent on the microstructure of the saltcrete. This is in turn dependent on the proportions of the mixture, the temperature, and the time of hydration. Under some circumstances, large fly ash contents may increase the permeability of the hardened wasteform.

\subsection{Accelerated Aging Tests.}

Aging tests designed to compare different cementitious materials were apparently based on ASTM D 559 (Standard Test Methods for Wetting and Drying Compacted Soil-Cement Mixtures) and D 560 (Standard Test Methods for Freezing and Thawing Compacted Soil-Cement Mixtures). "ASTM 559 and 560" were mentioned in the report Introduction as being recommended by the NRC for durability assessment (we assume these are D 559 and D 560). 
D 559 stipulates a moist curing $(100 \% \mathrm{RH})$ at $21^{\circ} \mathrm{C}$ for 7 days, followed by immersion in water for 5 hours, then heating in a $71^{\circ} \mathrm{C}$ oven for 42 hours. Loose material is brushed away and mass loss determined. The immersion-heating cycle is repeated 12 times. Specimens are cylinders 4 inches in diameter by 4.58 inches high.

D 560 stipulates moist curing at $21^{\circ} \mathrm{C}$ for 7 days, followed by a 24 -hour freezing period at $23{ }^{\circ} \mathrm{C}$, then thawing in the moist room for 23 hours. Loose material is brushed away and mass loss determined. The freezing-thawing cycle is repeated 12 times. The specimen configuration is like D 559.

The test methods reported here differed substantially from these, but the variations were probably reasonable for the particular application to saltcrete storage conditions. However, some of the details of the test methods may have had important effects on the results and interpretations that were not mentioned in the report.

Two experimental programs were run, one with samples of waste salt (actual salts) and one with salt made from commercially available reagents (surrogate salts) formulated to approximate waste salt. Both sets of samples were exposed to a wetting-and-drying test and a freezing-and-thawing test. Each experimental condition was represented by two replicate specimens.

\subsubsection{Actual Salts}

The wetting and drying test on actual salts differed from D 559 in that the temperature range of the cycle was narrower $\left(40\right.$ to $55^{\circ} \mathrm{C}$ ) and the wetting cycle was at $95 \% \mathrm{RH}$ rather than immersion in water. Specimens were cycled two times and were not brushed before determining mass and volume changes.

There were small but statistically significant changes in volume and large changes in mass after two cycles. The mean volume change over all mixtures was $-1.09 \pm 0.62 \%(95 \%$ confidence interval). The mean mass change was $-28.45 \pm 1.57 \%$. Volume-change differences among mixtures were not significant when analyzed in a one-way analysis of variance (see following table). Mass-loss differences among mixtures could not be analyzed statistically because the values of the individual replicates were not reported.

\begin{tabular}{|l}
\hline \begin{tabular}{l}
\hline Analysis of Variance of Volume Change, Actual Salts, Wetting-and-Drying Test, Data from Table \\
3.3.1.1.2-1
\end{tabular} \\
\hline Source of Variation
\end{tabular}


These changes probably reflect dehydration of the specimens. The $95 \% \mathrm{RH}$ wetting condition is probably not enough to truly rehydrate the specimens, while the $55^{\circ} \mathrm{C}$ drying condition is quite adequate to dry out specimens of this size. This test is probably not too useful for evaluating the swelling because it does not simulate the conditions of the saltcrete in halfcrates very well. NOTE THAT SALTCRETE CONTAINS 32\% WATER!

Freezing-and-thawing tests involved 2 days at $-20{ }^{\circ} \mathrm{C}$ followed by 2 days at $55^{\circ} \mathrm{C}$ for two cycles. Volume changes among mixtures were significant when analyzed in a one-way analysis of variance (see following table). Mass losses could not be analyzed for mixture-dependent effects because individual replicates were not reported, but these probably were not significant. The average mass loss was $8.0 \%$. Individual mixtures ranged from $-21.05 \%$ to $-23.74 \%$ mass loss.

\begin{tabular}{|c|c|c|c|c|c|}
\hline \multicolumn{6}{|c|}{$\begin{array}{l}\text { Analysis of Variance of Volume Change, Actual Salts, Freezing-and-Thawing Test, Data from } \\
\text { Table 3.3.1.2.2-1 }\end{array}$} \\
\hline Source of Variation & DF & Sum of Squares & $\begin{array}{l}\text { Mean } \\
\text { Square }\end{array}$ & F & $\mathrm{P}$ \\
\hline Among Material Types & 7 & 937.4379 & 133.92 & 247 & 0.001 \\
\hline Replications & 8 & 4.3273 & 0.541 & & \\
\hline Total & 15 & 941.7652 & & & \\
\hline
\end{tabular}

From the freezing and thawing results, Connell et al. concluded that Class F fly ash contributed to a reduction in swelling. Some pure portland cement mixtures and Class $\mathrm{C}$ fly ash containing mixtures swelled considerably. The amount of swelling is comparable to that observed in halfcrates.

Although only two Class $\mathrm{F}$ mixtures were included, the results do appear to support this conclusion. The effect was fairly strong in the comparison between Type I and Type I+Class $F,(\Delta V$ $=17.0 \%$ vs $-2.3 \%)$, but was not so strong in the Type $\mathrm{V}$ and Type $\mathrm{V}+\mathrm{Class} F$ comparison $(\Delta \mathrm{V}=$ $1.06 \%$ vs $-2.28 \%$ ) comparison. The difference in both comparisons was statistically significant.

The analysis does not support the conclusions about Class $\mathrm{C}$ fly ash. Two of the three Class $\mathrm{C}$ mixtures expanded either less than the control cement mixture or the difference was not significant. In one comparison the increase in volume was significant (Type I/II vs Type I/II+Class $C$ ).

Comparisons among the three types of portland cement showed the Type I to expand considerably more than the Types $\mathrm{I} / \mathrm{II}$ or $\mathrm{V}\left(17 \%\right.$ vs $5.2 \%$ and $1.1 \%$, respectively). Only $\mathrm{C}_{3} \mathrm{~A}$ contents of these cements were reported, but these correlated with the observed behavior. The Type I cement contains $12 \% \mathrm{C}_{3} \mathrm{~A}$, and the Types I/II and $\mathrm{V}$ cements contain $6 \%$ and $5 \%$, respectively. This strongly suggests that $\mathrm{C}_{3} \mathrm{~A}$ is an important property.

\subsubsection{Surrogate Salts}

Freezing and thawing of surrogate-salt specimens was done at $-12^{\circ} \mathrm{C}$ and $55^{\circ} \mathrm{C}$, respectively (i.e., slightly narrower range). Considerable volume change did occur (average over all specimens of 
$5.78 \%$ ), but experimental error, as measured by differences among replicates, was large relative to differences among means of the materials examined (see ANOVA in following table). Mass loss was probably due to drying condition at $55^{\circ} \mathrm{C}$ and does not give us much insight into the mechanism of deterioration.

\begin{tabular}{|c|c|c|c|c|c|}
\hline \multicolumn{6}{|c|}{$\begin{array}{l}\text { Analysis of Variance (ANOVA) of Volume Change, Surrogate Salts, Freezing-and-Thawing Test, } \\
\text { Data from Table 3.3.2.2.2-1 }\end{array}$} \\
\hline Source of Variation & $\mathrm{DF}$ & Sum of Squares & $\begin{array}{l}\text { Mean } \\
\text { Square }\end{array}$ & $\mathrm{F}$ & $\mathrm{P}$ \\
\hline Among Material Types & 5 & 31.5291 & 6.3058 & 1.30 & 0.375 \\
\hline Replications & 6 & 29.1344 & 4.8557 & & \\
\hline Total & 11 & 60.6635 & & & \\
\hline
\end{tabular}

\subsubsection{Discussion/Conclusions}

The wetting-and-drying test may not be providing data that are applicable to the cause of swelling in halfcrates. The specimens probably do not really fully wet under the conditions of the test, so the effect of wetting and drying is probably not really shown.

The freezing-and-thawing test may not really be a test of freezing and thawing since the water in the specimen has a high concentration of solutes and may not actually freeze. The cause of the apparent freezing-and-thawing effect is plausibly a crystal growth phenomenon that occurs because of the alternate cold-warm conditions. The idea is that crystals grow when solubility is reduced by decreasing temperatures. Increasing temperature redissolves some of the crystals completely (the smaller ones) when the specimen is warmed, and the larger crystals are only partially redissolved. When cooled again, the larger crystals then serve as crystallization sites for the dissolved material. The effect then is to grow large crystals at the expense of small ones. Since the matrix is rigid at this point, there will be a volume increase around the growing crystal and the creation of voids in the region of the dissolving small crystals. Since the matrix cannot collapse around the voids created, then there is a net volume increase of the specimen.

The pattern of results of the actual-salt tests suggests that calcium aluminates in the cement and fly ash contribute to the volume-change phenomenon. Given the high concentrations of sulfate and chloride ion in the salt, it seems likely that either calcium sulfoaluminate or calcium chloroaluminate, both reaction products involving calcium aluminates in cement, are involved. WES experience has been that, under these conditions, calcium chloroaluminate forms and calcium sulfoaluminate does not. Calcium chloroaluminate is considered to be a mildly expansive phase when it exists in concrete, but is not usually considered to be responsible for deterioration. Conceivably a crystallization phenomenon, such as described in the preceding paragraph, is operative.

The somewhat sporadic nature of the volume-change problems could be due to differences in temperature-cycling history among halfcrates, differences in salt composition, and differences in water content. 


\section{REFERENCE}

Poole, T. S. 1993. Stability of Calcium Chloroaluminate and Calcium Sulfoaluminate Phases in Hydraulic-Cement Mixtures. Miscellaneous Paper SL-93-2, U. S. Army Engineer Waterways Experiment Station, Vicksburg, MS. 


\section{MEMORANDUM FOR RECORD}

SUBJECT: Scoping Study of Simulated Saltcrete

1. Background. Following a site visit to the Rocky Flats Facility (DOE RF) in Apr 94, the U. S. Army Engineer Waterways Experiment Station (WES) team identified the crystalline phase darapskite in data from XRD analyses of saltcrete samples. The data were part of a study of saltcrete failure being performed by DOE RF contractors. The hypothesis evolved that darapskite contributed to observed expansion of saltcrete and failure of crates containing saltcrete. The WES team initiated a scoping study of simulated saltcrete to confirm that this phase would form from the saltcrete system, and to gain a better appreciation for the properties of saltcrete in various conditions.

2. Simulated Saltcrete.

a. A mixture intended to simulate the saltcrete being made at Rocky Flats was prepared at 1600 on 5 May 94. Two batches were made. Proportions are summarized in the following tabulation. The first batch was used to make a 2- by 2- by 11-in. prism and to fill two 28 -ml Nalgene vials. The second batch was used to mill ten 28-ml vials and eight split PVC-pipe molds. The prism and PVC specimens were left uncovered. The vials were snap capped. Four vials were put in a $55{ }^{\circ} \mathrm{C}$ incubator. All specimens were labeled with CTD No. 940107.

\begin{tabular}{||l|c|}
\hline \hline Mixture Proportions. \\
\hline Material & Mass (g) \\
\hline \hline Portland cement - 920297 & 500 \\
\hline $\mathrm{NaNO}_{3}$ - reagent grade & 360 \\
\hline $\mathrm{NaCl}$ - reagent grade & 55 \\
\hline $\mathrm{Na}_{2} \mathrm{SO}_{4}$ - reagent grade & 170 \\
\hline Water (tap) & 400 \\
\hline Total & 1485 \\
\hline
\end{tabular}

b. It was intended for the mixture to contain $50 \%$ salt loading and for the relative proportion of the three salts to be $72 \% \mathrm{NaNO}_{3}, 17 \% \mathrm{Na}_{2} \mathrm{SO}_{4}$, and $11 \% \mathrm{NaCl}$. By mistake, the proportions were $62 \% \mathrm{NaNO}_{3}, 29 \% \mathrm{Na}_{2} \mathrm{SO}_{4}$, and $9 \% \mathrm{NaCl}$, with a total salt loading of $39.4 \%$. This difference may be important. It was intended to proportion the salts to fall in the darapskite field of the three-salt phase diagram (Ericksen and Mrose $1970^{1}$ ). If all of the salts are equally soluble, then the starting

\footnotetext{
${ }^{1}$ The American Mineralogist 55:1500-1517.
} 
point is slightly in the thenardite field. Given the slowly soluble nature of $\mathrm{Na}_{2} \mathrm{SO}_{4}$, the starting point may really be in the darapskite field anyway.

c. The prism will be left open to the air until setting occurs, then stripped from the mold, bagged, and length-change measurements taken. Material in the nalgene vials will be used for XRD analysis.

d. The portland cement (CTD 920297) was a Type I with a very high $\mathrm{C}_{3} \mathrm{~A}$ content. This was used in hopes of getting an expansive reaction to occur. The report written by Connell (EG\&G, August 1993) indicated that high $\mathrm{C}_{3} \mathrm{~A}$ materials tended to expand more than low $\mathrm{C}_{3} \mathrm{~A}$ materials. Properties are summarized below.

\begin{tabular}{||l|l||l|l||}
\hline \hline \multicolumn{4}{|l|}{ Properties of Type I Portland Cement, 920297. } \\
\hline $\mathrm{SiO}_{2}$ & $19.6 \%$ & $\mathrm{Na}_{2} \mathrm{O}$ & 0.26 \\
\hline $\mathrm{Al}_{2} \mathrm{O}_{3}$ & $5.7 \%$ & $\mathrm{~K}_{2} \mathrm{O}$ & 1.23 \\
\hline $\mathrm{Fe}_{2} \mathrm{O}_{3}$ & $2.0 \%$ & $\mathrm{C}_{3} \mathrm{~A}$ & $13 \%$ \\
\hline $\mathrm{CaO}$ & $63.7 \%$ & $\mathrm{C}_{3} \mathrm{~S}$ & $55 \%$ \\
\hline $\mathrm{MgO}$ & $2.7 \%$ & $\mathrm{C}_{2} \mathrm{~S}$ & $14 \%$ \\
\hline $\mathrm{SO}_{3}$ & $3.5 \%$ & $\mathrm{C}_{4} \mathrm{AF}$ & $6 \%$ \\
\hline $\begin{array}{l}\text { Loss on } \\
\text { Ignition }\end{array}$ & $0.8 \%$ & $\begin{array}{l}\text { Blaine } \\
\text { Fineness }\end{array}$ & $366 \mathrm{~m}^{2} / \mathrm{kg}$ \\
\hline
\end{tabular}

3. Time of Setting and Appearance of Specimens. Specimens cured at $55^{\circ} \mathrm{C}$ had set, as measured by touch, after about 17 hours. Samples left at room temperature were set when checked at about 0900 on 9 May 94 ( 3 days, 17 hours). There was bleeding of brine through small cracks in the PVC molds. This bleed was clear; i.e., no cement paste present. The 11-in. prism had receded in its mold by about $2 \mathrm{~mm}$ from the top edge, but had not pulled away from the sides. Clear brine had climbed out of the mold, standing in puddles around the mold.

\section{Strength.}

a. Specimens were removed from the 1-in.-diameter PVC molds at test ages and sawed into cylindrical specimens $1 \mathrm{in}$. long. Compressive strength was measured on the Tinius-Olsen 60,000-lb machine. The cross-sectional surface was $0.785 \mathrm{in}^{2}$. Data are summarized in encl 1.

b. Two things were evident from the strength data. First, strengths were continuing to increase at the time of the last test age and had reached a reasonably high strength. Second, the bottom specimen always showed higher strengths than the three specimens taken from the upper part of the specimen, indicating that significant settling had occurred in the mixture after casting. 


\section{Length Change, Warm-Cold Cycles.}

a. Specimens cured at $55^{\circ} \mathrm{C}$ in sealed vials were demolded after 3.5 days, allowed to equilibrate to room temperature $\left(23^{\circ} \mathrm{C}\right)$ and length was measured at a marked point on the circumference of the cylinder with a vernier caliper. Two replicate measurements were made at each age. Specimens were then placed in a refrigerator at $1{ }^{\circ} \mathrm{C}$ for 24 hours. Specimens were not sealed to prevent water loss. Specimens were removed from the refrigerator and allowed to equilibrate to $23^{\circ} \mathrm{C}$ and were measured again. This cycle was repeated for four days. 'Three specimens were treated this way. Two.others were left at $23{ }^{\circ} \mathrm{C}$ throughout the test. Results are summarized in encl 2. Length change was linear up to 4 days, when the specimens disintegrated. Length change was about $14 \%$ at this point.

b. Another set of specimens that had been cured at $23^{\circ} \mathrm{C}$ since mixing ( 7 days) were exposed to a similar temperature cycling regimen. These results are also summarized in encl 2 . Some variations in the cycle are noted on Figure 2. Specimens were kept in plastic bags to prevent desiccation. Three specimens were temperature cycled and three were left at $23^{\circ} \mathrm{C}$. Length change of the temperaturecycled specimens sometimes reached as much as $4 \%$ per cycle, with specimens finally disintegrating after five cycles at a length change of about $16 \%$. There was a small but measurable shrinking of specimens as they warmed from $1{ }^{\circ} \mathrm{C}$ to $23^{\circ} \mathrm{C}$ (as noted on Figure 2, encl 2).

c. Conspicuous white crystals were evident on the broken surfaces of the disintegrated specimens. Broken surfaces of the compressive-strength specimens that had not been temperature cycled also contained white crystals, but they were much smaller. These crystals were identified by SEM as darapskite.

6. Length Change, Immersed vs. Bagged. One 70-mm specimen was immersed in deionized water when it was 7 days old. The 3- by 3- by 11-in. specimen was kept in a plastic bag with a moist paper towel. Results are summarized in encl 3. The immersed specimen increased in length in an approximately linear way through 45 days, when the test was terminated. Length change was about $2.5 \%$ at 43 days. The specimen broke on removal from water at 53 days. A considerable amount of material had. leached out of the specimen during this time and settled on the bottom of the beaker. When dry, the specimens were very light in weight, although no density determinations were made. There was a brownish crust on the outside of the specimen. The bagged specimens changed length very slowly, reaching $0.19 \%$ after 104 days. There was a slight shrinkage to $0.16 \%$ when measured at 208 days, but this could have been the result of some drying of the specimen.

\section{X-ray Diffraction Analysis of Samples.}

a. Pete Burkes did X-ray diffraction analysis of samples of saltcrete after $24 \mathrm{hr}$ and $90 \mathrm{hr}$ of hydration. He also looked at the residue from the material that crept out of the molds onto the desk top. The 24-hr sample contained darapskite, $\mathrm{NaCl}$, and $\mathrm{NaNO}_{3}$, but no $\mathrm{NaSO}_{4}$ (thenardite) was detected. The 90-hr sample contained the same phases, but calcium hydroxide was also present. The crust from the desk top contained darapskite, $\mathrm{NaNO}_{3}$, and $\mathrm{NaCl}$. Calcium chloroaluminate was not seen until the material had reached time of setting. 
SUBJECT: Scoping Study of Simulated Saltcrete

b. The specimen that was immersed for 53 days was also analyzed. The outer brownish crust was mostly calcite, but ettringite and quartz were also identified. The interior of the specimen contained ettringite, portlandite, $\mathrm{CSH}$, and a trace of calcite. The solids that settled out of the water were halite, calcite, and darapskite.

3 Encls
TOY S. POOLE, PhD

Concrete Technology Division

Structures Laboratory 


\begin{tabular}{|c|c|c|c|}
\hline $\begin{array}{l}\text { Age } \\
\text { (days) }\end{array}$ & Specimen* & $\begin{array}{l}\text { Strength } \\
\text { (psi) }\end{array}$ & Mean Strength (psi) \\
\hline \multirow[t]{3}{*}{4} & not logged & 178 & \\
\hline & not logged & 181 & \\
\hline & not logged & 202 & 187 \\
\hline \multirow[t]{4}{*}{6} & 1 & 393 & \\
\hline & 2 & 439 & \\
\hline & 3 & 400 & \\
\hline & 4 & 615 & 462 \\
\hline \multirow[t]{4}{*}{8} & 1 & 765 & . \\
\hline & 2 & 597 & \\
\hline & 3 & 729 & \\
\hline & 4 & 917 & 752 \\
\hline \multirow[t]{4}{*}{12} & 1 & 948 & \\
\hline & 2 & 1018 & \\
\hline & 3 & 1000 & \\
\hline & 4 & 1268 & 1059 \\
\hline \multirow[t]{4}{*}{23} & 1 & 1618 & \\
\hline & 2 & 1392 & \\
\hline & 3 & 1668 & \\
\hline & 4 & 2089 & 1692 \\
\hline
\end{tabular}

* $1=$ cut from top of specimen, $4=$ cut from bottom of specimen.

Page 1 of 2 pages

Encl 1 to Encl 4 to Encl 1 


\section{Mean Strength vs. Time, $23^{\circ} \mathrm{C}$}

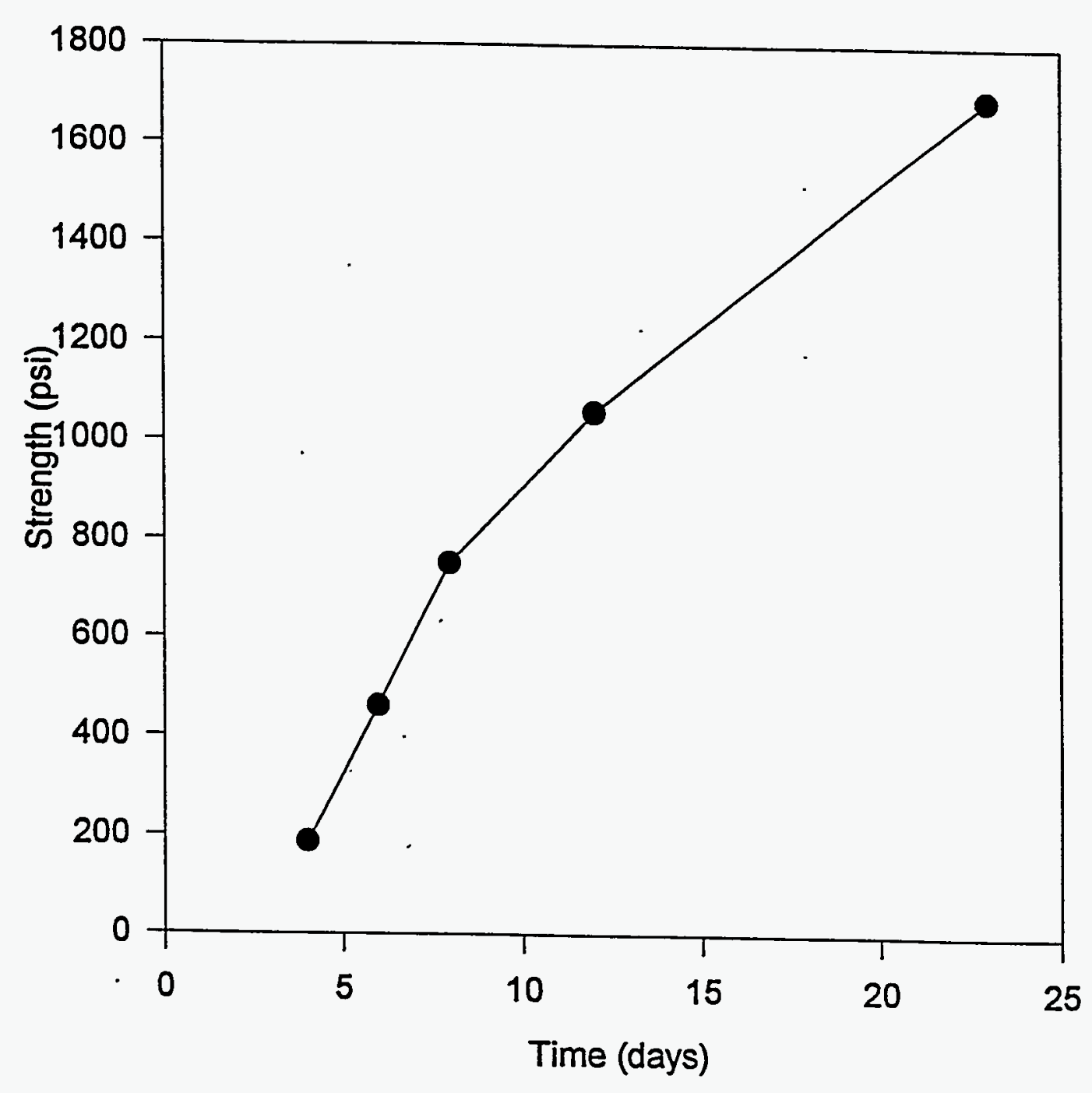

c:IspwIrf002.spw

Strength Development

Page 2 of 2 Pages 


\begin{tabular}{|c|c|c|c|c|c|}
\hline \multicolumn{6}{|c|}{$\begin{array}{l}\text { Table 2. Length-change data for specimens cured at } 55^{\circ} \mathrm{C} \text {, then } \\
\text { temperature cycled. Five specimens. Data plotted on Figure } 1 \text { of } \\
\text { following page. }\end{array}$} \\
\hline \multirow{2}{*}{$\begin{array}{l}\text { Age (days) } \\
1\end{array}$} & \multicolumn{2}{|c|}{$\begin{array}{l}\text { Not Temperature } \\
\text { Cycled }(\Delta L, \%)\end{array}$} & \multicolumn{3}{|c|}{$\begin{array}{l}\text { Temperature Cycled } \\
(\Delta L, \%)\end{array}$} \\
\hline & 0.15 & 0.20 & 2.40 & 2.30 & 3.70 \\
\hline 2 & 0.15 & 0.00 & 6.80 & 6.20 & 6.60 \\
\hline 3 & & 0.75 & 9.80 & 9.90 & \\
\hline 4 & & 0.65 & 14.0 & 13.7 & \\
\hline
\end{tabular}

\begin{tabular}{|c|c|c|c|}
\hline Age (days) & $\begin{array}{l}\text { Temperature Constant } \\
23^{\circ} \mathrm{C}\end{array}$ & $\begin{array}{l}\text { Temperature Cycled } \\
1^{\circ} \mathrm{C} \text { to } 23^{\circ} \mathrm{C}\end{array}$ & Comments \\
\hline 6 & 0.00 & 0.00 & \\
\hline 7 & 0.00 & 0.90 & \\
\hline 8 & 0.03 & 3.30 & \\
\hline 9 & 0.03 & 7.20 & no temp. cycl day $9-10$ \\
\hline 10 & 0.00 & 7.60 & measured cold \\
\hline 10.2 & & 7.00 & measured warm \\
\hline 11 & 0.07 & 12.40 & measured cold \\
\hline 11.2 & & 11.70 & measured warm \\
\hline 12 & 0.00 & 16.00 & \\
\hline
\end{tabular}

Length-Change with Temperature Cycling

Page 1 of 3 Pages

Encl 2 to Encl 4 to Encl 1 


\section{Figure 1. Length Change for Temperature-Cycled Specimens}

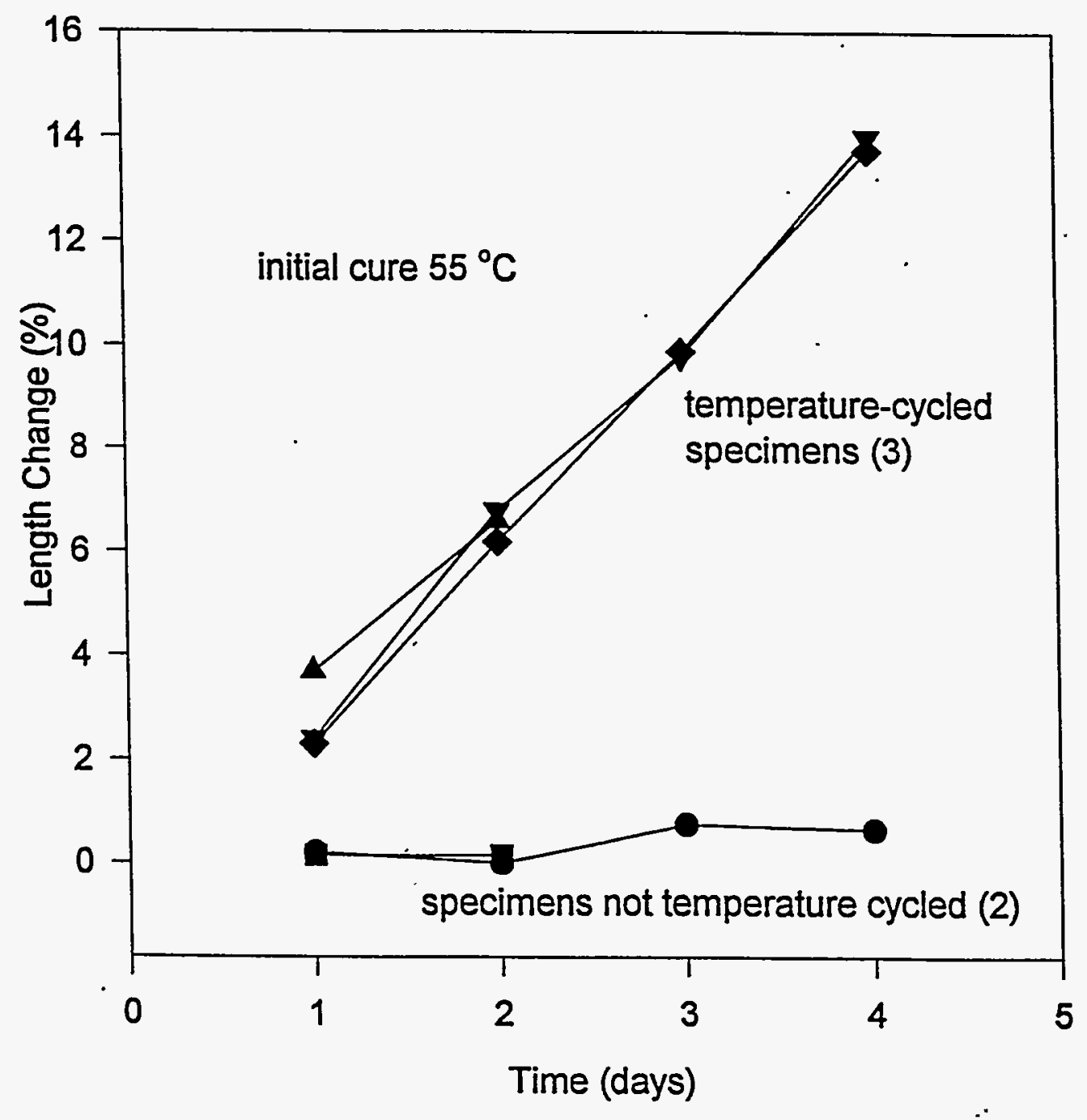

c:Ispwlrfo01.spw

Length-Change with Temperature Cycling

Page 2 of 3 Pages 
Figure 2. Length Change for Temperature-Cycled Specimens.

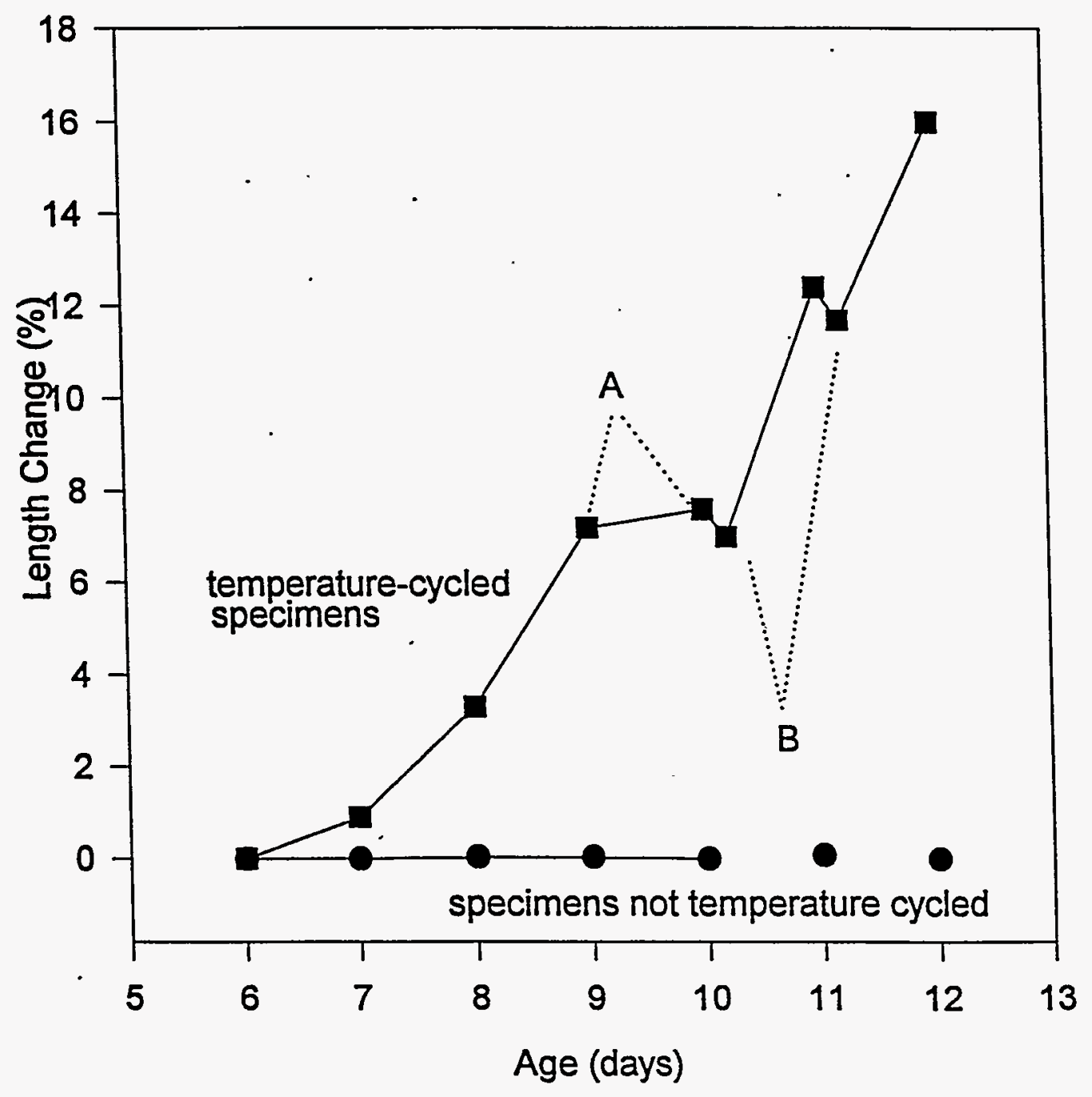

A - not temperature cycled between days 9 and 10 .

B - On days 10 and 11 , specimens measured cold, then warm. 


\begin{tabular}{|c|c|c|c|}
\hline \multicolumn{4}{|c|}{$\begin{array}{l}\text { Table 4. Comparison of length change of bagged and immersed } \\
\text { specimens. }\end{array}$} \\
\hline \multicolumn{2}{|c|}{ Immersed } & \multicolumn{2}{|c|}{ Bagged } \\
\hline age (days) & $\begin{array}{l}\text { length change } \\
(\%)\end{array}$ & age (days) & $\begin{array}{c}\text { length change } \\
(\%)\end{array}$ \\
\hline 7 & 0.00 & 5 & 0.000 \\
\hline 8 & 0.03 & 6 & 0.052 \\
\hline 9 & 0.00 & 7 & 0.072 \\
\hline 10 & 0.07 & 8 & 0.085 \\
\hline 11 & 0.17 & 9 & 0.092 \\
\hline 13 & 0.27 & 10 & 0.100 \\
\hline 14 & 0.37 & 11 & 0.109 \\
\hline 15 & 0.37 & 12 & 0.116 \\
\hline 18 & 0.54 & 13 & 0.119 \\
\hline 20 & 0.65 & 14 & 0.126 \\
\hline 21 & 0.66 & 15 & 0.129 \\
\hline 26 & 1.01 & 18 & 0.135 \\
\hline 27 & 1.12 & 20 & 0.138 \\
\hline 29 & 1.22 & 21 & 0.140 \\
\hline 33 & 1.54 & 26 & 0.153 \\
\hline 34 & 1.57 & 33 & 0.166 \\
\hline 35 & 1.33 & 40 & 0.172 \\
\hline 36 & 1.68 & 43 & 0.172 \\
\hline 40 & 2.18 & 108 & 0.187 \\
\hline 43 & 2.49 & 208 & 0.159 \\
\hline
\end{tabular}

Comparison of immersed and bagged specimens

Page 1 of 2 Pages

Encl 3 to Encl 4 to Encl 1 